\title{
JURNAL \\ INFO KESEHATAN
}

(HEALTH INFORMATION JOURNAL)

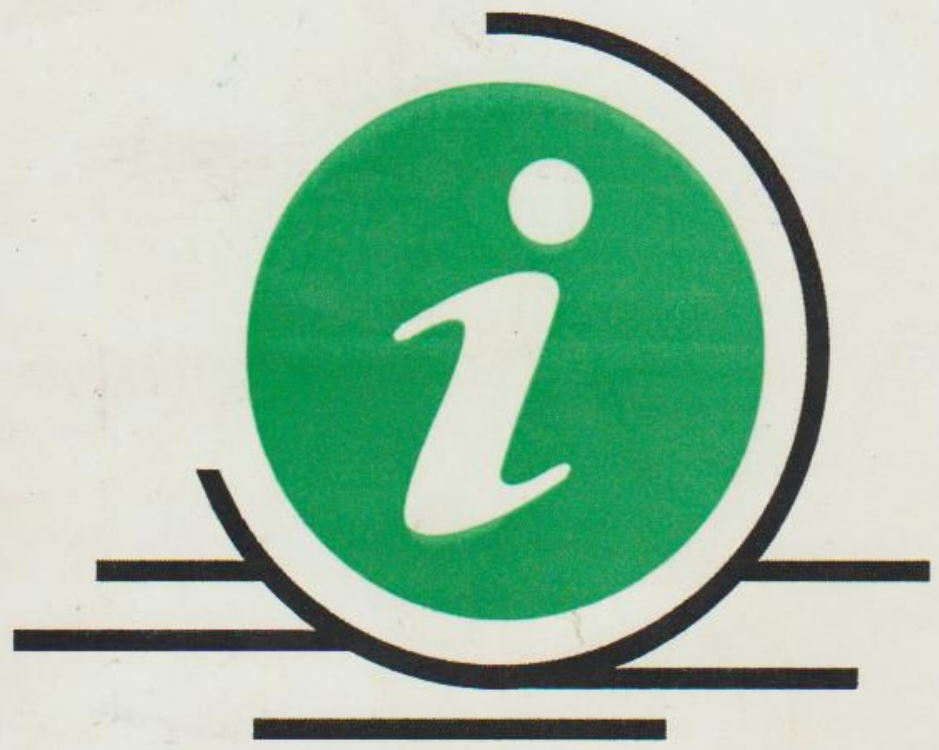

Diterbitkan oleh

Unit Penelitian Dan Pengabdian Masyarakat

Politeknik Kesehatan Kupang

\begin{tabular}{|c|c|c|c|c|c|}
\hline $\begin{array}{c}\text { JURNAL } \\
\text { INFO KESEHATAN }\end{array}$ & VOLUME 5 & NOMOR 1 & $\begin{array}{c}\text { HALAMAN } \\
1-84\end{array}$ & $\begin{array}{c}\text { KUPANG } \\
\text { Desember 2008 }\end{array}$ & $\begin{array}{c}\text { ISSN } \\
0216-504 \mathrm{X}\end{array}$ \\
\hline
\end{tabular}




\section{JURNAL INFO KESEHATAN (HEALTH INFORMATION JOURNAL)}

VOLUME 5, No. 1, DESEMBER 2008, hlm. 1 - 84

ISSN : 0216-504X

Terbit dua kali setahun Bulan Juli dan Desember. Berisi tulisan yang diangkat dari hasil penelitian dan kajian analisis kritis di bidang Kesehatan.

Pemimpin Redaksi

Wakil Pemimpin Redaksi

Penyunting Ahli

Penyunting Pelaksana

Sekretariat
: Yuanita C. L. Rogaleli, SSi, M. Kes

: Karolus Ngambut, SKM

: 1. Prof. H. Kuntoro, dr., Dr. PH

2. DR. Achiryani, DNSc

3. Sabina Gero, SKp.,MSc

4. Drs. Nikolaus Hayon, M. Humaniora

: 1. Rafael Paun, SKM, M.Kes

2. Dra. Elisma, Apt, MSi

3. R. H. Kristina, SKM, M.Kes

4. Drs. Jefrin Sambara, Apt, MSi

5. Drg. Jeffrey Jap, M.Kes

6. Beatrix Soi, SST., SPd.,M Kes

: 1. Hendrikus Mbira, Amd. S.Pd (Keperawatan Ende)

2. Welhelmus Mu, SST Keperawatan Waingapu)

3. Sabinus B. Kedang, SKep. NS (Keperawatan Kupang)

4. Siprianus Singga, ST (Kesehatan Lingkungan)

5. Maria L.M. Indrawat, SPd (Farmasi)

6. Ferdinan Fankari, SS:T (Kesehatan Gigi)

7. M. F. Nining Kosad, SST, M. Kes (Kebidanan)

8. Agustina Setia, SST, M Kes (Gizi)

9. Tutek Sulstyowat, SPd, (Direkitorat)

10. Hareni Kapitan (Direkitorat)

Alamat Penyunting dan Tata Usaha : Sekretariat Jurnal Info Kesehatan Poltekkes Kupang JI. EI Tari II Liliba Kupang Telp/Fax (0380) 8080488, 881788, 881045

Jurnal Info Kesehatan diterbitkan pertama kali Bulan Desember 2004 oleh Unit Penelitian dan Pengabdian Masyarakat Politeknik Kesehatan Kupang

Penyunting menerima sumbangan tulisan yang belum pernah diterbitkan dalam media lain, Naskah diketik di atas kertas A4 spasi ganda sepanjang lebih kurang 15 halaman dengan format seperti tercantum pada halaman kulit dalam belakang. Naskah yang masuk dievaluasi dan disunting untuk keragaman format, istilah dan tata cara lain. 


\title{
PENGALAMAN MAHASISWA YANG MENGAMBIL CUTI AKADEMIK KARENA HAMIL
}

\author{
Sabina Gero *
}

\begin{abstract}
Students in a college like Health Department of Kupang Polytechnic have specific problems like as students pregnant. Health Polytechnic of Kupang rule, called Norma and Tolok Ukur, has statement about pregnant student on chapter academic holiday. Before 2008, the rule was very strict, many female students became victims, as drop out students because they can't show a married letter. Pregnant students are increased every year. This study want to know the experience of pregnant students who taking an academic holyday for 2 semesters. The aims of this study are to identified students psychomotor during pregnant, their parents actions about the cases, students actions in academic holidays and students actions after coming on the study again. The advantage of this study is to revision the rule of Norma \& Tolok Ukur health Polytechnic of Kupang. The comperation between female and male student in this college is $4: 1$.

The study method was qualitative phenomenology, doing in 7 (seven) program studies, which have students to take place the singular semester on 2008, after academic holyday. All of the participants are 18 (eighteen) students who came back to school after pass their academic holiday. The participants answer the essay test in home and giving the researcher after finish answer the essay. The researcher analysis the answer by categorical, themes and the conclusions.

The results were all of the female pregnant students were very distress emotional during the cases, their parents want them to finish their study. All of the female students want to finish their study. Also after they begun the singular semester they were very happy, more concentration, and higher motivations than before.
\end{abstract}

Keywords : Pregnant student; experiences, academic holiday, Norma \& Tolok Ukur

\section{PENGANTAR}

Permintaan cuti akademik karena hamil pada Poltekkes Depkes Kupang, setiap tahun selalu ada, bahkan grafiknya cenderung meningkat. Kejadian ini membuat binggung para dosen dan pembimbing akademik, serta para pengambil keputusan, ketua program studi, ketua jurusan dan direktur serta para pembantu direktur. Dampak meningkatnya jumlah mahasiswa yang cuti karena hamil nampak pada prosentasi lulusan setiap tahun ajaran, yang selanjutnya bisa berakibat meningkatnya angka drop out mahasiswa, oleh karena cuti yang dijalani dapat menurunkan minat dan motivasi menyelesaikan kuliah. Keadaan ini memprihatinkan tidak saja bagi orang tua mahasiswa tetapi juga lembaga Poltekkes dan seluruh sivitas akademika. Masalah kehamilan mahasiswa selama masih dibangku kuliah menjadi masalah dan urusan semua pihak yang berhubungan langsung dengan kejadian itu.

Dalam pembahasan Norma dan Tolok Ukur Poltekkes Depkes Kupang, setiap tahunnya, selalu ada perdebatan panjang pada bab III, bagian keempat tentang Cuti Kuliah dan bab IV bagian keempat tentang Sanksi Akademik. Ada pro dan kontra dikalangan anggota senat ketika komisi Akademik, yang membahas revisi Norma dan 
Tolok Ukur menyampaikan hasil pembahasan mereka dalam rapat pleno. Demikian kerasnya diskusi mengenai Cuti Kuliah dan Sanksi Akademik menyebabkan rapat pleno menjadi berlarut-larut karena tidak segera mendapat kata sepakat untuk 2 (dua) aturan ini. Sulitnya mengambil keputusan untuk 2 aturan ini, terbukti dengan tidak adanya revisi dua aturan ini dalam Norma dan Tolok Ukur Poltekkes Depkes Kupang tahun 2005, 2006 dan 2007. selama 3 (tiga) tahun berturut-turut rapat senat sudah mengangkat masalah ini, baru pada tahun 2008 , Senat Poltekkes Depkes Kupang berhasil merubah 2(dua) aturan tersebut secara bermakna dan dengan pikiran yang lebih relitistis. $\mathrm{Hal}$ ini didorong pula oleh adanya mahasiswa perempuan yang meninggal dan setelah diusut lebih jauh, disebabkan oleh karena aborsi dengan cara yang tidak sehat atau keracunan kehamilan, dan mahasiswa laki-laki nekad melakukan bunuh diri karena pacarnya hamil.

Pada April 2008, Senat Poltekkes Depkkes Kupang mengubah isi aturan tentang Cuti Kuliah dan Sanksi Akdemik. Cuti Kuliah pada pasal 14 menjelaskan tentang Cuti akademik yang direncanakan dan Cuti Akdemik yang tidak direncanakan. Cuti akademik yang direncanakan diberikan dengan alas an sakit lebih dari 1 bulan, tugas Negara, hamil dan atau melahirkan. Cuti tipe ini, direncanakan oleh mahasiswa atau atas kemauan sendiri, diperhitungkan dalam masa studi, diberi untuk jangka waktu 2 (dua) semester secara berurutan atau tidak, hanya dapat diberikan apabila mahasiswa telah mengikuti 2(dua) semester masa studi. Mengenai Sanksi Akademik, dijelaskan bahwa sanksi diberikan mulai dari yang teringan sampai ke yang paling berat yaitu teguran lisan dan tertulis, skorsing dan pemberhentian tetap/pemutusan studi. Berubahan bermakna aturan berhubungan dengan Cuti Akademik, pasal 14, 1.f, tertulis "hamil dan menghamili dikenakan cuti 2 semester", pada Norma Tolok Ukur tahun sebelum ( 2006 $\& 2007$ ), pasal 14, 1 .f, tertulis " cuti karena hamil dan menghamili dapat mengikuti proses belajar mengajar kembali bila telah menunjukkan surat nikah". Perubahan diatas menunjukkan bahwa mahasiswa yang cuti karena hamil dapat kembali kuliah tanpa menujukkan surat nikah. Hal ini sangat bermakna, sebab biasanya mahasiswa yang hamil menemukan kesulitan untuk kembali kuliah oleh karena tidak dapat mengurus pernikahan dengan berbagai alasan yang sangat pribadi sifatnya ( Norma dan Tolok Ukur tahun, 2006, 2007 dan 2008).

Tabel 1. Data lulusan Poltekkes Depkes Kupang dalam 2 tahun ( 2006 dan 2007)

\begin{tabular}{|l|c|c|}
\hline JURUSAN & TAHUN 2006 & TAHUN 2007 \\
\hline Keperawatan & $57.6 \%$ & $61.9 \%$ \\
Kebidanan & $46 \%$ & $66.6 \%$ \\
Kesling & $55.7 \%$ & $78.7 \%$ \\
Keperawatan Ende & $73.7 \%$ & $48.3 \%$ \\
Kep Waingapu & $68 \%$ & $81.9 \%$ \\
Farmasi & $135 \%$ & $100 \%$ \\
Kesehatan Gigi & $87.5 \%$ & $100 \%$ \\
\hline
\end{tabular}

Nampak prosentasi lulusan yang sangat kurang di tahun 2006 , namun meningkat dalam tahun 2007, atau prosentasi baik ditahun 2006, tetapi menurun di tahun 2007 misalnya Program studi keperawatan Ende. Penyumbang terbesar rendahnya prosentasi lulusan setiap tahunnya berasal dari cuti akademik mahasiswa karena hamil.

Menghadapi masalah kehamilan mahasiswa, pihak pendidikan sering menghadapi kesulitan mengambil keputusan. Berbagai situasi ditemukan dilapangan. Ada mahasiswa yang melaporkan kehamilannya bersama orang tua, ada mahasiswa yang kehamilannya diketahui oleh dosen/pendidikan dari teman, saudara, keluarga dekat, ada pula mahasiswa yang kehamilannya didiamkan saja sementara tetap mengikuti perkuliahan. Penanganan masalah kehamilan mahasiswa oleh pendidikan, biasanya merujuk pada Norma dan Tolok Ukur tahun berjalan. Jalan buntu biasanya ditemukan saat perkawinan tidak 
dapat diselesaikan, karena berbagai hal terutama karena perbedaan agama, laki-laki tidak mau bertanggung jawab, keluarga dua belah pihak tidak sepakat mengurus pernikahan, masalah adat-istiadat (belis), dII. Peliknya persoalan pernikahan, jarang diketahui oleh pendidikan/ dosen yang tidak terlibat secara langsung seluruh proses pernikahan mahasiswa bersangkutan. Biasanya setelah menemukan jalan buntu, orang tua menyampaikan ke pihak pendidikan untuk meminta kebijaksanaan dalam masalah yang dihadapi. Keputusan pendidikan pertamatama melihat aturan dalam Norma dan Tolok Ukur, juga mendengar penjelasan keluarga/orang tua, sehingga aturan dalam Norma dan Tolok Ukur tidak diterapkan secara mutlak pada semua mahasiswa. Pada kasus-kasus khusus misalnya pada mahasiswa keperawatan, pendidikan mengambil keputusan dengan memindahkan mahasiswa ke Program Studi Ende atau Waingapu dan sebaliknya pula.

Kasus kehamilan mahasiswa ditemukan hampir pada semua Jurusan dan Program Studi yang ada di Politeknik Kesehatan Kupang. Jika untuk mahasiswa keperawatan dapat dicari jalan keluar bagi mahasiswa hamil yang tidak dapat diurus pernikahannya, sedang bagi mahasiswa dari jurusan lain yang tidak ada alternativ Program Studi ditempat lain, seperti Jurusan Kebidanan, Jurusan Kesehatan Lingkungan, Ketua Jurusan dan dosen pembimbing akademik menjadi sulit. Disatu pihak orang tua menuntut anaknya untuk menyelesaikan kuliah, dilain pihak pendidikan terikat pada aturan yang dibuat dan bagaimana mentaati aturan itu demi kepentingan orang banyak yang dilayani yaitu mahasiswa sendiri. Oleh karena sulitnya keadaan ini bagi jurusan lain diluar keperawatan, maka Senat Poltekkes Depkes Kupang, tahun 2008 mengubah aturan cuti hamil mejadi lebih manusiawi dengan "hamil dan atau menghamili dikenakan cuti 2(dua) semester". Kalimat aturan yang bermakna sangat terbuka terhadap tanggapan dan interprestasi semua orang, baik mahasiswa, orang tua, dosen. Sesungguhnya kalimat ini mau menjelaskan bahwa mahasiswa yang hamil boleh masuk kuliah kembali tanpa mesti menunjukkan SURAT NIKAH. Menunjukkan surat nikahlah yang selama ini menjadi persoalan utama mahasiswa tertunda wisuda, menghilang dari kampus atau bahkan sampai drop out. Kondisi ini perlu disikapi dengan cerdas dan bijak, sebab menjadi hamil pada anak muda sekarang sudah menjadi model, atau hal yang biasa-biasa saja.

Arus informasi bebas dalam era globalisasi dengan banyaknya situs-situs porno di internet, majalah; CD blue film, sinetro TV tentang perkawinan dini, seks pra nikah, kawin cerai, dan perselingkuhan; narkoba berpengaruh pada gaya hidup orang muda. Orang muda dalam masa krisisnya memasukki masa dewasa, perbedaan gaya hidup di desa, kabupaten dan kota, hidup sendiri di kos jauh dari orang tua, kurang mampunya menyaring informasi-informasi yang datang dan diterima, menyebabkan perkembangan perilaku yang tidak sehat, seperti seks bebas. Selain itu orang tua sulit menangani masalah anak-anaknya karena perbedaan paradigma. Orang tua sering tidak mau menerima keputusan anak-anak, dan menginginkan anakanak mengikuti kehendak orang tua. $\mathrm{Hal}$ ini merambat pada pemilihan jodoh atau teman hidup bagi anak-anak mereka. Konflik yang terjadi antara orang tua dan anak (mahasiswa) dalam hal paradigma, jodoh, membuat anak menjadi lebih nekat dan mengambil jalannya sendiri, tanpa berkompromi dengan orang tua.

Penelitian ini dilaksanakan dalam tahun 2008 , bersamaan dengan diperlakukan Norma dan Tolok Ukur tahun 2008 yang baru saja berubah aturan cuti. Mahasiswa yang terlibat dalam penelitian ini pada saat kejadian hamil, masih diberlakukan aturan sebelum tahun 2008 , yang mengharuskan mereka untuk masuk kuliah kembali dengan menunjukkan surat nikah. Penelitian ini bertujuan mengidentifikasi pengalaman mahasiswa yang menjalani cuti 
akademik karena hamil. Manfaat penelitian untuk institusi Poltekkes Depkes Kupang sebagai bahan masukkan bagi Jurusan dan Program Studi dalam menangani kasus-kasus kehamilan mahasiswa; bagi para Pembimbing Akademik bagaimana menghadapi mahasiswa yang bermasalah karena hamil; dan bagi anggota senat sebagai bahan masukkan untuk merevisi Norma dan Tolok Ukur tahun 2009 yang lebih perspektif gender. Hal ini dihubungkan dengan kondisi Poltekkes Depkes Kupang saat ini, dimana perbandingan mahasiswa perempuan dan laki-laki $=4: 1$.

\section{METODE PENELITIAN}

Desain penelitian ini berupa suatu studi kualitativ dengan metode fenomenologi, untuk menjawab pertanyaan riset " sejauhmana pengalaman mahasiswa yang menjalankan cuti akademik karena hamil"? Penelitian untuk melihat filosofi dasar dari cuti akademik karena hamil pada mahasiswa yang sedang aktiv kuliah. Mahasiswa yang mengalami cuti karena hamil jumlahnya meningkat, walau dalam perhitungan kelompok besar mahasiswa jarang. Hamil merupakan fenomena sosial, karena bagi seorang mahasiswa yang belum menikah, mestinya kehamilan tidak terjadi. Kehamilan yang dialami seorang mahasiswa perempuan, tidak dapat ditutupi keadaannya, karena perutnya akan terus membesar disamping gejala kehamilan lainnya yang tak dapat disembunyikan. Akhirnya, semua teman, dosen, keluarga dan orang lain akan mengetahui kehamilan seseorang. Besarnya pengaruh sosial bagi seorang mahasiswa yang hamil, bagi peneliti merupakan suatu fenomena yang baik untuk dipelajari. Partisipan, yang adalah mahasiswa yang sudah menjalani cuti akademik karena hamil akan diminta memberi pengalamannya selama cuti. Pengalaman itu merupakan informasi berharga bagi peneliti, yang selain sebagai dosen, anggota/ketua Senat dan Pimpinan, agar dapat mengambil makna dan nilai dari penelitian ini dikembangkan dalam aturan yang berlaku serta perannya sebagai pembimbing akademik.

Partisipan dalam penelitian ini adalah mahasiswa yang sudah aktiv kembali kuliah setelah menjalani cuti akademik karena hamil, yang tersebar pada Jurusan dan Program Studi, masingmasing jurusan Keperawatan, Kebidanan, Kesehatan Lingkungan, Gizi, Farmasi dan Kesehatan Gigi Kupang, Program Studi Keperawatan Ende dan Program Studi Keperawatan Waingapu.

\section{Grafik 1. Karakteristik Partisipan}

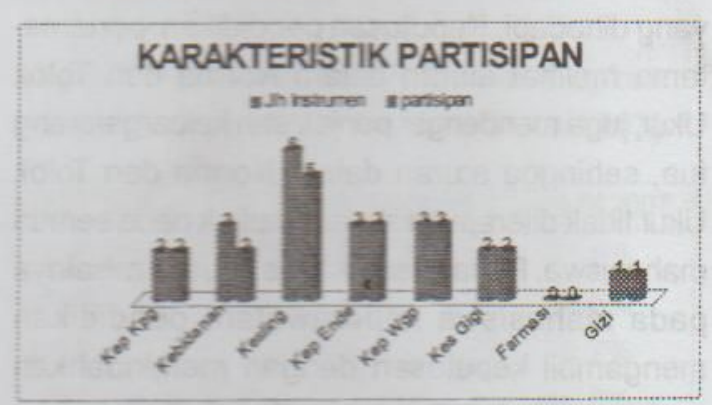

Data ini memperkuat informasi tentang prosentasi lulusan, dimana partisipan dari Jurusan Farmasi tidak ada, sebab dalam 2 (dua) tahun berturut-turut, 2006 dan 2007, lulusan Farmasi $135 \%$ dan $100 \%$. Partisipan terbanyak berasal dari Jurusan Kesehatan Lingkungan dan partisipan terkecil berasal dari Jurusan Gizi yang baru berdiri selama 3 tahun dan belum menghasilkan lulusan.

Pemilihan partisipan secara purposive, berdasarkan data yang ada di Jurusan dan Prodi, mahasiswa yang melakukan registrasi kembali pada semester genap, Februari/Maret 2008, setelah cuti akademik karena hamil. Pengumpulan data dilakukan dengan mengirimkan daftar pertanyaan/essay kepada partisipan untuk dijawab secara jujur. Jawaban atas pertanyaan diberikan dalam bentuk ketikan atau ditulis tangan, kemudian menyerahkan jawaban kepada peneliti dalam amplop tertutup. Sebelum menerima amplop pertanyaan/essay, partisipan diminta menandatangani inform consent. Kriteria partisipan adalah mahasiswa yang kembali aktiv kuliah setelah menjalani cuti 2 (dua) semester dengan 
alasan hamil \& melahirkan. Partisipan yang tidak mengembalikan lembar jawaban dinyatakan keluar dari penelitian ini. Dari 20 (dua puluh) lembar pertanyaan yang disebarkan, $18(90 \%)$ responden mengembalikan lembar jawaban kepada tim peneliti.

Data yang masuk dianalisa dengan lebih dahulu ditentukan kategori pengalaman yang ingin diketahui sesuai essay tes. Jawaban responden 1 (satu) sampai 18 (delapan belas) dicatat per kategori, dan tema yang sering muncul dari 18 responden diangkat sebagai jawaban atas pertanyaan riset ini. Masing-masing responden diberi kode untuk mempermudah analisa data. Responden memberijawaban tanpa tekanan atau arahan, benar-benar pengalaman yang dialami selama menjalani cuti. Tema-tema yang ditemukan dimasukkan dalam pola-pola tertentu, yang selanjutnya oleh peneliti diformalasikan kembali untuk menjawab pertanyaan riset. Tema-tema yang jarang muncul diangkat sebagai suatu yag perlu diperhatikan lebih jauh. Keabsahan penelitian diperoleh dari partisipan yang terlibat dalam penelitian, sesuai kriteria penelitian. Tim peneliti adalah dosen yang bekerja di direktorat. Reliabilitas didapat dengan memperhatikan konteks penelitian ini. Subyektivitas partisipan sangat dihargai dan diperhatikan, subyektiv peneliti dihindari. Peraturan Norma dan Tolok Ukur menjadi fokus utama dalam menganalisa hasil penelitian ini. Kesimpulan hasil penelitiaan ini dibuat dengan memperhatikan tujuan penelitian.

\section{HASIL PENELITIAN DAN PEMBAHASAN Hasil Penelitian}

Peneliti mengkategorikan jawaban responden dalam 6 (enam) kategori, masing-masing 1) hamil semenara masih kuliah; 2) pengambilan keputusan terhadap kehamilan; 3) sikap orang tua dan mahasiswa terhadap kehamilan; 4) sikap pendidikan terhadap kehamilan mahasiswa; 5) menjalani cuti akademik dan 6) mengikuti proses belajar mengajar pasca cuti akademik.

Hamil sementara masih kuliah, dikenal responden dari, tidak datang haid, tanda dan gejala hamil, danmemastikan hamil dengan melakukan tes urin kehamilan yang dilakukan sendiri. Kehamilan ini terjadi setelah lebih dari 1 kali berhubungan seksual ( 13 responden). Perasaan tertekan yang dominan dialami ketika mengetahui dirinya hamil adalah takut, malu, bersalah, stres-depresi-frustrasi, putus asa, dan menyesal. Kehamilan yang terjadi tidak langsung diterima (13 responden), bahkan paling lama diterima setelah usia kehamilan 4 bulan ( $R-18$ ). Setelah pasti hamil, responden menyampaikan lebih dahulu ke pacar (14 responden), ada 4 responden yang merasa berat menyampaikan kehamilannya ke pacar sehingga menyampaikannya lewat teman. Reaksi pacar setelah mendengar kehamilan yang terjadi bervariasi, mulai dari perasaan tertekan, menolak bertanggung jawab (3 responden), minta menggugurkan kandungan ( 2 responden), menerima dan siap bertanggung jawab (6 responden).

Pengambilan keputusan terhadap kehamilan, responden tidak menyembunyikan kehamilannya (15 responden) kepada orang tua, sebagai orang yang bertanggung jawab atas dirinya, namun ada 3 responden menyembunyikan kehamilannya terhadap orang tua, baik sendiri menyampaikan (12 responden) atau lewat keluarga, orang tua dari pacar, pacar dan lewat surat/telepon. Reaksi orang tua terhadap kehamilan anaknya, marah dan kecewa (15 responden). Orang tua memutuskan untuk segera proses menikah (7 responden), meminta pacar bertanggung jawab ( 5 responden), melapor kependidikan (4 responden) dan melepas tanggung jawab (R3; R13).

Sikap orang tua dan mahasiswa terhadap kehamilan, mencari informasi menyelesaikan kasus ini lewat buku Norma dan Tolok Ukur (16 responden). Orang tua mendorong untuk melapor ke pendidikan ( 8 responden), hanya ada 1 responden ( $\mathrm{R} 15$ ) dipanggil oleh dosen karena melihat perubahan pada diri mahasiswa. Menghadapi kehamilan, sikap mahasiswa langsung 
menyampaikan ke pendidikan bersama pacar (6 responden), takut dan malu dikeluarkan dari pendidikan (10 responden), merasa biasa saja, sebab hamil bukan sesuatu yang tabu ( $R 6$; R11).

Sikap pendidikan terhadap kehamilan mahasiswa, reaksi pendidikan rata-rata kecewa, marah dan kaget ( 8 responden) dan menganjurkan mahasiswa yang bermasalah karena hamil untuk mengurus cuti akademik untuk urus pernikahan ( 8 responden) dan ada 2 responden yang masalah kehamilannya digantung begitu saja. Terhadap sikap pendidikan mahasiswa menerima dengan tabah dan merasa pantas menerima hukuman ini ( 15 responden), sedang ada 2 (dua) mahasiswa yang kecewa dan merasa tak pantas menerima keputusan pendidikan untuk cuti 2 semester.

Menjalani cuti akademik, selama menjalani cuti mahasiswa melakukan pekerjaan-pekerjaan rumah tangga sambil menjaga kehamilan, membaca buku-buku dan majalah, menjalani proses menikah. Kehamilan diperiksa di dokter praktek, bidan, puskesmas (11 responden), poli hamil RSUD dan ada 1 orang yang tidak memeriksakan kehamilannya.
Proses menikah yang diharuskan dari pendidikan, 13 responden menikah, 4 responden tidak menikah dan 1 responden tidak menjawab. Mengurus anak ada 9 responden senang punya anak, 2 orang mengatakan anaknya diurus oleh orang tua, sendiri bersama suami 3 orang, 4 orang diurus mertua dan 9 responden tidak menjawab siapa yang mengurus anaknya. Aturan menikah dan memasukkan surat nikah sebagai prasyarat untuk mengikuti kuliah kembali, 9 responden menyatakan sesuai, ada 4 responden mengatakan tidak setujua hal ini menjadi aturan baku. Seluruh responden ingin melanjutkan/ menyelesaikan studinya ( $100 \%$ ).

Mengikuti proses belajar mengajar pasca cuti akademik. Responden merasa senang aktiv belajar kembali, tidak sulit bergabung di kelas baru (13 responden). Disamping itu ada rasa sulit, minder, repot, sibuk, susah, cape, binggung dan stres pada awal-awal kuliah. Motivasi belajar kembali 12 responden mengatakan meningkat, sedang 6 responden mengatakan biasa saja seperti sebelum cuti.

Tema-tema yang diangkat dari 6 (enam) kategori ini berturut-turut dalam tabel $2-7$,

Tabel 2. Distribusi frekuensi berdasarkan tema

\begin{tabular}{|c|c|c|c|}
\hline Tema & Responden & Frekuensi & F-relatif \\
\hline Berhubungan seks $>1$ kali & $2-4 ; 6-11 ; 15-18$ & 13 & $72,2 \%$ \\
\hline $\begin{array}{l}\text { Berhubungan seks }>1 \text { kall } \\
\text { Berhubungan seks } 1 \text { kali }\end{array}$ & $1,5,12,13,14$ & 5 & $27,8 \%$ \\
\hline $\begin{array}{l}\text { Berhubungan seks } 1 \text { Kall } \\
\text { Total/Jumlah }\end{array}$ & & 18 & $100 \%$ \\
\hline $\begin{array}{l}\text { Total/Jumlah } \\
\text { Tes urin untuk kehamilan sendiri : PST }\end{array}$ & $1-4$ dan $6-18$ & 17 & $94,4 \%$ \\
\hline $\begin{array}{l}\text { Tes urin untuk kehamilan semuim. To } \\
\text { USG }\end{array}$ & 5 & 1 & $5,6 \%$ \\
\hline $\begin{array}{l}\text { USG } \\
\text { Total/Jumlah }\end{array}$ & & 18 & $100 \%$ \\
\hline $\begin{array}{l}\text { Total/Jumlah } \\
\text { Berniat dan sudah mencoba gugurkan kandungan }\end{array}$ & $1-4 ; 6 ; 8 ; 11-13 ; 15-16$ & 11 & $61,1 \%$ \\
\hline Berniat dan sudah mencoba guguan & $5,7,9,10,14,17,18$ & 7 & $38,9 \%$ \\
\hline $\begin{array}{l}\text { Tidak berniat gugurkan kannumigan } \\
\text { Total/Jumlah }\end{array}$ & & 18 & $100 \%$ \\
\hline $\begin{array}{l}\text { Total/Jumlah } \\
\text { Merasa takut, malu, bersalah, \&menyesal }\end{array}$ & $1 ; 3-10 ; 12-18$ & 16 & $88,8 \%$ \\
\hline $\begin{array}{l}\text { Merasa takut, malu, } \\
\text { Merasa biasa-biasa saja }\end{array}$ & 11 & 1 & $5,6 \%$ \\
\hline $\begin{array}{l}\text { Merasa biasa-biasa saja } \\
\text { Merasa tidak dapat menerima,frustrasi, depresi }\end{array}$ & $\frac{11}{2}$ & 1 & $5.6 \%$ \\
\hline $\begin{array}{l}\text { Merasa tidak dapat menermina, } \\
\text { Total/Jumlah }\end{array}$ & & 18 & $100 \%$ \\
\hline $\begin{array}{l}\text { Total/Jumlah } \\
\text { Langsung menerima kehamilan }\end{array}$ & $6 ; 8 ; 11 ; 12 ; 14$ & & \\
\hline $\begin{array}{l}\text { Langsung menerima Kenamimai } \\
\text { Tidak segera menerima kehamilan (minggu-bulan) }\end{array}$ & $1-5 ; 7 ; 9-10 ; 13 ; 15-18$ & & \\
\hline $\begin{array}{l}\text { Tidak segera menerima Kendimilah } \\
\text { TotalJumlah }\end{array}$ & & 18 & $100 \%$ \\
\hline
\end{tabular}

Kesimpulan : kehamilan ini terjadi setelah lebih dari 1 kali berhubungan $(72,2 \%)$. Mahasiswa melakukan tes kehamilan sendiri ( 94,4$)$. Pada awalnya ada tengat, malu dan bersalah $(88,8 \%)$.

menggugurkan ( $68,1 \%)$, hal ini berhubungan dengan raswa tidak segera bisa menerima kehamilan ini $(72,1 \%)$ 
Tabel 3. Distribusi frekuensi berdasarkan tema dalam kategori "PENGAMBILAN KEPUTUSAN TERHADAP KEHAMILAN"

\begin{tabular}{|l|l|c|c|}
\hline \multicolumn{1}{|c|}{ Tema } & \multicolumn{1}{|c|}{ Responden } & Frekuensi & F-Relatif \\
\hline Berniat menyampaikan ke orang tua & $1 ; 2 ; 4-7 ; 9-12 ; 14-18$ & 15 & $83,3 \%$ \\
\hline Sembunyikan dg orang tua & $3 ; 8 ; 13$ & 3 & $16,6 \%$ \\
\hline Total/Jumlah & & 18 & $100 \%$ \\
\hline Segera menyampaikan pacar & $1-7 ; 9-15 ; 18$ & 15 & $83,3 \%$ \\
\hline Berat, tidak mau sampaikan ke pacar & $8 ; 16 ; 17$ & 3 & $16,6 \%$ \\
\hline Total/Jumlah & & 18 & $100 \%$ \\
\hline Reaksi pacar minta digugurkan & $6 ; 10$ & 2 & $11,1 \%$ \\
\hline Tidak menerima dan menolak bertanggung jawab & $2 ; 3 ; 13$ & 3 & $16,6 \%$ \\
\hline Pacar siap bertanggung jawab, senang, biasa saja & $4 ; 5 ; 9 ; 11 ; 14 ; 16 ; 18$ & 6 & $33,3 \%$ \\
\hline Pacar : kaget, takut, bersalah, binggung, marah & $1 ; 2 ; 7 ; 8 ; 12 ; 15 ; 17$ & 7 & $38,8 \%$ \\
\hline Total/Jumlah & & 18 & $100 \%$ \\
\hline
\end{tabular}

Kesimpulan :Kehamilan segera disampaikan ke pacar $(85,3 \%)$, berniat menyampaikan ke orang tua (85,3\%). Reaksi pacar, kaget, takut dan bersalah $(38,8 \%)$, siap bertanggung jawab (33,3\%), menolak bertanggung jawab (16,6\%)

Tabel 4. Distribusi frekuensi berdasarkan tema dalam kategori "TINDAKAN BERSAMA ORANG TUA TERHADAP KEHAMILAN"

\begin{tabular}{|l|c|c|c|}
\hline \multicolumn{1}{|c|}{ Tema } & Responden & Frekuensi & F-Relatif \\
\hline Mengurus pernikahan segera & $6 ; 8 ; 9 ; 11 ; 14 ; 15 ; 17$ & 7 & $38,8 \%$ \\
\hline Melapor ke pendidikan & $1 ; 2 ; 4 ; 7 ; 18$ & 5 & $27,7 \%$ \\
\hline Meminta tanggung jawab pacar & $5 ; 10 ; 12 ; 16$ & 4 & $22,2 \%$ \\
\hline Orang tua lepas tangan & 3,13 & 2 & $11,1 \%$ \\
\hline Total/Jumlah & & 18 & $100 \%$ \\
\hline Membaca "Norma \& Tolok Ukur" & $3-18$ & 16 & $88,8 \%$ \\
\hline Tidak membaca "Norma \& Tolok Ukur" & 1,2 & 2 & $11,1 \%$ \\
\hline Total/Jumlah & & 18 & $100 \%$ \\
\hline
\end{tabular}

Kesimpulan : mencari informasi dalam Buku Norma dan Tolok Ukur ( $88,8 \%)$, Keputusan orang tua untuk segera mengurus pernikahan (38,8\%), melapor ke pendidikan (27,7\%), meminta pertanggung jawaban pacar (22,2\%)

Tabel 5. Distribusi frekuensi berdasarkan tema dalam kategori "SIKAP PENDIDIKAN TERHADAP KEHAMILAN YANG TERJADI"

\begin{tabular}{|l|l|l|c|}
\hline \multicolumn{1}{|c|}{ Tema } & \multicolumn{1}{c|}{ Responden } & Frekuensi & F-Relatif \\
\hline Segera mengurus cuti akademik & $2 ; 9 ; 10 ; 14 ; 17$ & 5 & $27,7 \%$ \\
\hline Segera mengurus pernikahan & $8 ; 15$ & 2 & $11,1 \%$ \\
\hline Mengantung masalah & $5 ; 6 ; 16$ & 3 & $16,6 \%$ \\
\hline Kaget,marah,kecewa & $1 ; 3 ; 4 ; 7 ; 11 ; 12 ; 13 ; 18$ & 8 & $44,5 \%$ \\
\hline Total/Jumlah & & \multicolumn{1}{c|}{18} & $100 \%$ \\
\hline
\end{tabular}

Kesimpulan : pendidikan bereaksi kaget, marah dan kecewa (44,5\%). Mengarahkan mahasiswa untuk urus cuti akademik ( $27,7 \%$ ), mengantung masalah yang terjadi $(16,6 \%)$ dan mengurus pernikahan $(11,1 \%)$ 
Tabel 6.Distribusi frekuensi berdasarkan tema dalam kategori

\begin{tabular}{|c|c|c|c|}
\hline Tema & Responden & Frekuensi & F-Relatif \\
\hline Menerima keputusan pendidikan & $1-5 ; 7-18$ & 17 & $94,4 \%$ \\
\hline Merasa kecewa & 6 & 1 & $5,6 \%$ \\
\hline Total/Jumlah & & 18 & $100 \%$ \\
\hline Merasa bahagia menikah & $1-2 ; 4 ; 7 ; 8 ; 10-12 ; 14-15 ; 17 ; 18$ & 12 & $66,6 \%$ \\
\hline Tidak menikah & $3 ; 5 ; 6 ; 13$ & 4 & $22,2 \%$ \\
\hline Bahagia dan tidak : fifty-fifty & $\frac{0,0,0,10}{9 ; 16}$ & 2 & $11,1 \%$ \\
\hline Total/Jumlah & & 18 & $100 \%$ \\
\hline Menikah bukan jalan keluar terbaik & $3 ; 6 ; 11 ; 13$ & 4 & $22,2 \%$ \\
\hline Menikah bisa lanjut kuliah & $1 ; 2 ; 4 ; 7$ & 4 & $22,2 \%$ \\
\hline Menikah,status jelas & $\frac{1 ; 2 ; 4 ;}{5 ; 8-10 ; 12 ; 14-18}$ & 10 & $55,5 \%$ \\
\hline Total/Jumlah & & 18 & $100 \%$ \\
\hline Ingin melanjutkan kuliah & $1-18$ & 18 & $100 \%$ \\
\hline Senang mempunyai anak & $1-4 ; 8-10 ; 12 ; 18$ & 9 & $50 \%$ \\
\hline Tidak berespon & $5-7 ; 11 ; 13-17$ & 9 & $50 \%$ \\
\hline Total/Jumlah & & 18 & $100 \%$ \\
\hline Mengurus anak sendiri \& suami & $9 ; 10 ; 17 ;$ & 3 & $16,6 \%$ \\
\hline Tidak berespon & $5-7 ; 11-16 ; 18$ & 15 & $83,3 \%$ \\
\hline & & 18 & $100 \%$ \\
\hline
\end{tabular}

Total/Jumlah

Kesimpulan : keputusan pendidikan diterima mahasiswa (94,4\%), menikah agar status jelas $(55,5 \%)$ ingin melanjutkan kuliah; menikah membahagiakan (66, menikah untuk melanjutkan studi (22,2\%) dan ma anak $50 \%$ sedang mengurus anak sendiri dan $22,2 \%$ mahasiswa tidak menikah.senang punya anak suami $16,6 \%$.

Tabel 7. Distribusi frekuensi berdasarkan tema dalam kategori

Tabel 7. Distribusi frekuensi berdasarkan tema dalam
"MENGIKUTI KULIAH KEMBALI PASCA CUTI"
\begin{tabular}{|l|l|c|c|}
\hline \multicolumn{1}{|c|}{ Tema } & Responden & Frekuensi & F-Relatif \\
\hline Senang \& tidak sulit kembali ke kelas & $1-4 ; 7 ; 10-12 ; 17 ; 18$ & 10 & $55,5 \%$ \\
\hline Sulit, merasa berbeban berat & $5 ; 6 ; 8 ; 9 ; 13-16$ & 8 & $44,5 \%$ \\
\hline Total/Jumlah & & 18 & $100 \%$ \\
\hline Motivasi belajar lebih kuat & $1-5 ; 7-10 ; 12 ; 15-17$ & 13 & $72,3 \%$ \\
\hline Motivasi belajar sama & $6 ; 11 ; 13 ; 14 ; 18$ & 5 & $27,7 \%$ \\
\hline Total/Jumlah & & 18 & $100 \%$ \\
\hline
\end{tabular}

Kesimpulan : motivasi mengikuti kuliah kembali lebih kuat (72,2\%); ada rasa senang dan tidak sulit bergabung kembali dengan kelas yang baru ( $55,5 \%)$, namun ada yang merasa sulit dan berbeban berat $(44,6 \%)$.

\section{Pembahasan}

Partisipan dalam penelitian ini, mengungkapkan riwayat kehamilan mereka terjadi setelah berhubungan seksual lebih dari 1 kali, $72,2 \%$," setelah beberapa kali berhubungan intim" (R2, R11, R17, R18), atau " setelah berhubungan berulang-ulang" (R.6). Kondisi ini jika dihubungkan dengan data remaja kota Kupang $31 \%$ sudah berhubungan seksual. Dalam hasil Survey Kesehatan Reproduksi Remaja Indonesia (SKKRI, tahun 2002-2003) pada 15 provinsi di Indonesia terhadap remaja perempuan dan laki-laki usia 15 -24 tahun menunjukkan remaja pria 5 kali lebih setuju melakukan hubungan seks pra nikah dari remaja putri ( $5: 1$ ), dan 2 kali lebih banyak remaja laki-laki berpeluang melakukan hubungan seksual pra nikah. Pengetahuan tentang kesehatan reproduksi tidak berpengaruh bermakna terhadap sikap remaja melakukan hubungan seksual pra nikah. Kehamilan diketahui mula-mula lewat tanda dan gejala hamil, selanjutnya $94,4 \%$ melakukan tes kehamilan sendiri, gunakan PST 
( kecuali R5). Hal ini sesuai dengan hasil SKKRI, bahwa remaja perempuan lebih banyak ( $50 \%$ ) tahu resiko hamil dengan sekali berhubungan seksual, dibanding remaja laki-laki ( $46 \%$ ), juga masa subur mereka. Remaja perempuan juga lebih banyak sudah pernah pacaran ( $75 \%$ ), dibanding remaja laki-laki. Setelah pasti hamil, membutuhkan waktu berminggu-minggu sampai bulan responden menerima kehamilannya, " ....awal pertama hamil tidak menerima, setelah dua bulan kehamilan baru iklas menerima" atau " ...setelah satu bulan, karena seolah tidak percaya yang terjadi ...., “...setelah satu bulan, karena masih muda dan belum tahu mengurus anak" ( $R 1,2,3,4,5, R 9,10, R 13, R 15,16,17,18)$. Perasaan yang dominan ketika mengetahui diri hamil yaitu takut, malu, bersalah dan menyesal $88,8 \%$. Dari kondisi ini, $68,1 \%$ responden berniat melakukan abortus, bahkan 1 responden sudah mencoba tindakan abortus, tapi gagal ( R6).

Dalam "Norma dan Tolok Ukur" tahun 2007 dan tahun-tahun sebelum, tentang cuti akademi dan sanksi-sanksi. Cuti kuliah (Bagian Keempat, Pasal 14, dari Norma dan Tolok Ukur tahun 2007) ayat 1 tentang cuti akademik, bagian $\mathrm{f}$, tertulis " cuti karena hamil dan menghamili dapat mengikuti proses belajar kembali bila telah menunjukkan surat nikah". Dampak aturan ini nampak pula pada adanya perasaan takut, malu, bersalah dan menyesal sampai berniat melakukan abortus bahkan mencoba mengugurkan (R6). Pacar responden tidak mau bertanggung jawab, ...." menuduh saya melakukan dengan orang lain" $(R 2,3,13)$, atau minta gugurkan kandungan ( $R 6$ \& 10). Mahasiswa yang saat ini kuliah kembali 4 (empat) orang ( $R 3, R 5, R 6, R$ 13) tidak mengurus pernikahan dan mengatakan "... proses menikah bagi mahasiswa yang hamil tidak merupakan jalan keluar, dan jangan jadikan menikah sebagai aturan baku..."( R3, R6). Selain ini, seluruh responden ingin menyelesaikan studinya ( $100 \%)$. Pengalaman ingin mengugurkan kehamilan dan ingin menyelesaikan kuliah adalah dua hal yang saling berhubungan. Mahasiswa tega ingin menggugurkan kandungannya kemungkinan akibat aturan yang memperbolehkan mahasiswa kembali kuliah jika dapat menunjukkan surat nikah. Menikah bagi sebagian responden, bukan merupakan jalan keluar terbaik pada kasus kehamilan. Menikah karena terpaksa demi aturan bagi seorang perempuan serupa dengan tindak kekerasan terhadap perempuan itu sendiri. Oleh sebab itu aturan dalam "Norma dan Tolok Ukur" perlu dievaluasi kembali dalam hal cuti akademik dan sanksi, agar lebih perspektiv gender. Ada perubahan dalam Norma dan Tolok Ukur tahun 2008 karena lebih perspektif gender, pada ayat 1, Cuti Akademik, bagian $f$ tertulis " Hamil dan menghamili dikenakan cuti 2 semester ". Dengan demikian memberi kesempatan kepada perempuan untuk dapat menyelesaikan studinya. Masa depan perempuan dapat diselamatkan.

Sebagai lembaga pendidikan tenaga kesehatan, Politeknik Kesehatan Depkes Kupang, merupakan pendidikan untuk menghasilkan tenaga yang siap pakai dalam keahlian kesehatan tertentu dan terdiri dari program Diploma I,II,III dan IV. Tenaga Kesehatan dalam UU no 23 tahun 1992, bertugas menyelenggarakan atau melakukan kegiatan kesehatan sesuai dengan bidang keahlian dan atau kewenangan tenaga kesehatan yang bersangkutan. Tugas seorang tenaga kesehatan terbilang berat, sebab lebih terhubung dengan orang sakit, contoh menjadi perawat, bidan, asisten apoteker, perawat gigi, nutrisian dan sanitarian. Etika moral seorang tenaga kesehatan penting terbentuk sejak awal menjadi mahasiswa. Pendidikan seorang tenaga kesehatan, berbeda dengan mendidik mahasiswa umum lainnya yang dilaksanakan di universitas, sekolah tinggi, dll. Hal ini telah kental terbentuk pada para dosen Poltekkes Kupang. Perbedaan paradigma dahulu dan sekarang perlu dihadapi dengan bijak. Hamil bagi seorang perempuan mestinya terjadi dalam keluarga. Selain itu, proses kehamilan membawa dampak besar bagi wanita hamil. Perubahan-perubahan pada fisik, mental seorang ibu hamil menimbulkan resiko- 
resiko tertentu bagi wanita hamil, misalnya keracunan kehamilan. Oleh karena itu, seorang ibu hamil hendaknya mendapatkan ketenangan pikiran, perasaan, dan pelayanan ante natal care yang baik. Tekan psikologis hebat yang dialami mahasiswa selama hamil, dapat berasal dari diri sendiri, pacar,orang tua, dosen/pendidikan, lingkungan sosial (teman-teman), merupakan tindak kekerasan pula.

Adanya pro dan kontra menangani kasus mahasiswa hamil pada setiap Jurusan dan Program Studi menyebabkan pendidikan melalui Pembimbing Akademik perlu lebih hati-hati menangani kasus mahasiswa hamil. Melihat pengalaman responden yang bervariasi menghadapi kehamilannya, seperti "menerima kehamilan dengan iklas"(R14) atau "menyembunyikan kehamilan" (R3); "hamil bukan hal yang tabu" (R11), " orang tua lepas tangan" (R13), "orang tua ingin proses menikah secepatnya" (R6, 8, 9, $11,14,15,17)$, disimpulkan bahwa mahasiswa yang hamil dapat dibagi dalam 3 tipe. Mahasiswa tipe pertama, dikategorikan sebagai biasa berhubungan intim dengan laki-laki, mahasiswa tipe kedua, sebagai ingin coba-coba, ingin tahu atau akibat pengaruh lingkungan teman sepergaulan, dan mahasiswa tipe ketiga, sebagai mahasiswa dengan kontrol diri lemah ketika berpacaran. Adanya 3(tiga) tipe mahasiswa ini, hendaknya dapat diidentifikasi oleh dosen Pembimbing Akademik tiap Jurusan dan Program Studi. Melalui proses identifikasi, pemecahan terhadap kasus mahasiswa hamilpun berbeda sesuai dengan ketiga tipe ini. Dengan mengidentifikasi tipe-tipe mahasiswa ini, pembimbingan dapat dikembangkan lebih intensiv. Bagi tipe mahasiswa yang biasa berhubungan dengan seorang laki-laki, perlu diberi pendampingan khusus, yang mungkin seorang psikolog, bukan hanya Pembimbing Akademik. Bagi mahasiswa tipe dua dan tiga, dapat dilaksanakan langsung oleh Pembimbing Akademik berkoordinasi dengan ketua jurusan, dll. Dengan demikian mahasiswa yang hamil dapat ditangani dengan baik dan efektiv. Pelayanan yang baik terhadap mahasiswa hamil dengan maksud agar mereka dapat menjaga kehamilannya dan pada waktunya dapat melahirkan dengan selamat dan sehat.

Politeknik Kesehatan Departemen Keseha$\tan$ Kupang, mempunyai jumlah mahasiswa perempuan berbanding laki-laki $=4: 1$, mahasiswa perempuan lebih besar 4 kali dari mahasiswa laki-laki. Potensial menemukan mahasiswa cuti akademik karena hamil cukup besar. Bagaimana dosen pembimbing akademik mencegah mahasiswanya hamil penting. Berbicara tentang kehamilan secara blak-blakan, menanyakan sudah punya pacar atau belum, siapa pacarnya saat ini, pada waktu bimbingan, sangat perlu. Menciptakan kondisi yang lebih terbuka antara mahasiswa dan dosen PA (Pembimbing Akademik) perlu sejak awal. Pembagian mahasiswa PAyang paten tidak berganti-ganti selama waktu kuliah, merupakan strategi yang dapat dipertimbangkan. Memberi waktu untuk mahasiswa yang ingin berkonsultasi, dan mewajibkan mahasiswa membaca aturan dalam Norma dan Tolok Ukur penting. Mengingatkan mahasiswa akan kerja keras orang tua serta mahalnya biaya SPP di Poltekkes Depkes Kupang, dapat menyadarkan mahasiswa akan tugas dan fungsinya di Poltekkes Depkes Kupang. Kreativitas dosen PA masing-masing untuk membuat mahasiswanya sadar selalu dapat mencegah terjadi kasus hamil dan menghamili dikalangan mahasiswa Poltekkes Depkes Kupang. (Proporsi mahasiswa perempuan: laki-laki $=80,3 \%: 19,7 \%$ atau 4:1. Data SIPTK Poltekkes Depkes Kupang tahun 2008)

Norma dan Tolok Ukur Poltekkes Depkes Kupang tahun 2009, akan dibahas revisinya dalam rapat senat pertama, April 2009. Dapatkah dipertimbangkan pemberian cuti yang cukup 1 (satu) semester, sesuai dengan kondisi dan kebutuhan mahasiswa? Merujuk hasil studi ini, yang menyatakan $100 \%$ mahasiswa yang cuti akademik karena hamil ingin melanjutkan kuliah, $72,2 \%$ motivasi lebih kuat, dan $55,5 \%$ merasa 
senang bergabung kembali dalam kelas. Hal mengurus anak $50 \%$ tidak memberikan jawaban, dan hanya 2 mahasiswa mengurus anak sendiri (R9,R17). Dapat disimpulkan, bahwa mahasiswa sesungguhnya belum siap menikah, berumahtangga dan punya anak sendiri. Kehamilan yang merupakan kecelakaan tanpa ada cinta dapat mendatangkan kesulitan bagi hidup berumah tangganya dimasa yg akan datang.

Ada hal tambahan yang perlu dibahas adalah tentang sanksi skrosing dan pemutusan studi dalam buku Norma dan Tolok Ukur tahun 2008. Jika terhadap yang hamil diberi cuti akademik agar dapat menyiapkan diri melahirkan dan menyusui bayi, maka bagi yang hamil saat setelah menyelesaikan semester VI dan PKL tertulis ditunda Ujian Akhir Program pada semester berikut. Hal inipun bisa dipertimbangkan kembali dengan pemberlakukan seperti pada kasus cuti akademik karena hamil. Hal yang sama perlu pertimbangan untuk kasus ketahuan hamil setelah yudisium UAP atau setelah wisuda, ijasah ditahan selama 1 semester. Jika peraturan untuk mahasiswa jalur khusus boleh hamil selama kuliah, maka dengan modifikasi rencana proses menikah pada keluarga dua belah pihak, maka mahasiswa dapat ikut wisuda dan menerima ijasah. Tentang hamil dan menghamili pada semester I dan II, perlu dipikirkan matang-matang. Sebagian dosen anggota senat mengatakan peristiwa hamil dapat menjadi contoh yang buruk jika dibiarkan bagi mahasiswa lain, namun jika setelah ketahuan kita langsung skrosing dan beri cuti, maka cara ini mungkin dapat dipertimbangkan.

\section{SIMPULAN DAN SARAN}

Kehidupan modern dan arus informasi bebas yang berkembang di Nusa Tenggara Timur, kota Kupang, khususnya anak muda (termasuk mahasiswa) menyebabkan informasi tentang seksualitas sangat vulgar dan dapat di akses dimana saja. Kehamilan mahasiswa selama masih kuliah sudah menjamur, tidak perlu ditutup- tutupi. Pemberian cuti akademik karena hamil selama 2 semester sesuai aturan dalam buku Norma dan Tolok Ukur 2007, atau sebelumnya, merupakan rujukan bagi mahasiswa dan orang tua untuk mengambil cuti hamil. Orang tua tetap mengharapkan anak perempuan mereka dapat menyelesaikan studinya. Selama cuti mahasiswa mengurus pekerjaan rumah tangga dan memeriksa kehamilannya di tenaga kesehatan. Setelah kembali aktiv mengikuti Proses Belajar Mengajar (PBM), mahasiswa lebih termotivasi dan berkonsentrasi untuk menyelesaikan studinya.

Saran-saran yang dapat diberikan antara lain, tingkatkan peran $\mathrm{PA}$, pendekatan $\mathrm{PA}-\mathrm{Maha}$ siswa lebih bersahabat dan secara terbuka berbicara tentang seksual dan kehamilan. Kenali tiga tipe mahasiswa, masing-masing mahasiswa yang bergaul bebas, mahasiswa yang suka cobacoba, dan mahasiswa yang ketahanan diri lemah, penting agar penanganan masalah lebih efektiv. Jika perlu, pekerjakan seorang psikolog sebagai pendamping mahasiswa berfungsi sebagai konsultan bagi mahasiswa yang bermasalah untuk tiap-tiap Jurusan/Prodi. Aturan yang berbasis gender penting diperhatikan. Orang tua bertanggung jawab atas anaknya selama di bangku kuliah, dan ingin anaknya tetap menyelesaikan kuliah. Norma dan Tolok Ukur tahun 2008 dapat direvisi jika disepakati dalam aturan tentang Cuti Akademik dan Sanksi-Sanksinya untuk menyempurnakan Norma dan Tolok Ukur 2009.

\section{DAFTAR PUSTAKA}

BULETIN GEMA PARTISIPASI PRIA, nO: 4NI/ 2007. "HAK REPRODUKSI WANITA". Jakarta: BKKBN PUSAT

BKKBN Nasional, 2007. PANDUAN PENGELOLAAN PUSAT INFORMASI \& KONSELING Kesehatan reproduksi remaja" (PIK-KRR). Jakarta: BKKBN PUSAT

BKKBN Nasional, 2006. "Pedoman Materi KIE" Jakarta: Direktorat advokasi dan KIE 
BKKBN NASIONAL, 2007. "Summary: Hasil Penelitian Keluarga Berencana \& Kesehatan Reproduksi”. Jakarta: BKKBN Nasional

DepDiknas RI, 1999. PP RINOMOR 60 TAHUN 1999, TENTANG PENDIDIKAN TINGGI" JAKARTA: DEPDIKNAS-RI

Depkes RI, 1992. UU RI NOMOR23 TAHUN 1992 TENTANGKESEHATAN. Jakarta: Depkes RI 2008. " PERATURAN MENTERI KESEHATAN RI NOMOR 890/MENKES/ PERNIII/2007, TENTANG ORGANISASI DANTATAKERJAPOLITEKNIKKESEHATAN". Depkes RI : Jakarta

Depkes RI, 1992. UURI NOMOR23 TAHUN 1992 TENTANG KESEHATAN. Jakarta: Depkes RI 2008. "PERATURAN MENTERI KESEHATAN RI NOMOR 890/MENKES/ PERNIII/2007, TENTANG ORGANISAS! DAN TATAKERJAPOLITEKNIK KESEHATAN". Depkes RI : Jakarta

Kristo, 2006. " Skripsi: Persepsi mahasiswa politeknik Kesehatan Poltekkes) kupang Jurusan Keperawatan mengenai Seksual Pra Nikah di Asrama Putri Poltekkes Jurusan Keperawatan di Kelurahan Liliba, Kecamatan Oebobo Kota Kupang". Kupang: Kristo Moleong, 2007, "Metodologi Penelitian Kualitatif edisi revisi" PT. Remaja Rosdakarya Bandung

POLTEKKES DepKes Kupang, 2008. NORMA DAN TOLOK UKUR PENYELENGGARAAN PENDIDIKAN DI POLTEKKES DEPKES KUPANG TAHUN 2008. Poltekkes Depkes: Kupang " NORMA DAN TOLOK UKUR PENYELENGGARAAN PENDIDIKANDI POLTEKKES DEPKES KUPANG TAHUN 2006. Poltekkes Depkes: Kupang " NORMA DAN TOLOK UKUR PENYELENGGARAAN PENDIDIKANDI POLTEKKES DEPKES KUPANG TAHUN 2007. Poltekkes Depkes: Kupang

POS KUPANG, JANUARI 2009. “ 31 PERSEN Remaja Kupang sudah berhubungan seks" percetakan PT Timor Media Grafika: Kupang

Sukmadinata, 2006, Penelitian Kualitatif, PT. Gramedia, Jakarta

UNFPA, 2004. " MODUL PELATIHAN : Penanggulangan Kekerasan Terhadap Perempuan di daerah konflik/Situasi Krisis". Jakarta: UNFPA

UNFPA, 2002. "KELUARGA BERENCANA, KESEHATAN REPRODUKSI, GENDER, dan Pembangunan Kependudukan" . Jakarta: UNFPA 